Pacific Journal of Mathematics

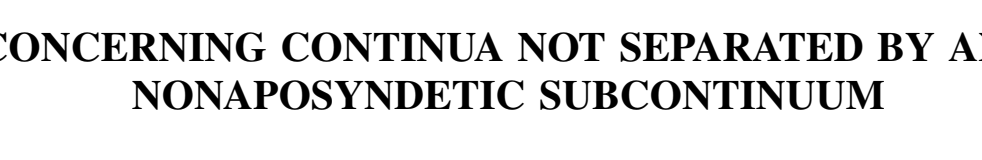




\section{CONCERNING CONTINUA NOT SEPARATED BY ANY NONAPOSYNDETIC SUBCONTINUUM}

\section{ELDON J. VOUGHT}

Certain theorems that apply to compact, metric continua that are separated by none of their subcontinua can be generalized and strengthened in those continua that are separated by none of their nonaposyndetic subcontinua. For those of the former type, if the continuum is aposyndetic at a point, it is locally connected at the point. The same conclusion is possible if the continuum is not separated by any nonaposyndetic subcontinuum. Also, if a continuum is separated by no subcontinuum and cut by no point, it is a simple closed curve. A second result of this paper is to prove that if no nonaposyndetic subcontinuum separates and no point cuts the continuum, then it is a cyclically connected continuous curve; in fact this yields a characterization of hereditarily locally connected, cyclically connected continua.

A third theorem characterizes an hereditarily locally connected continuum as an aposyndetic continuum that is separated by no nonaposyndetic subcontinuum. This is a somewhat stronger result than the known equivalence of hereditary local connectedness and hereditary aposyndesis.

A continuum is a closed, connected point set and the theorems of this paper are true for those continua that are compact and metric. If $x$ is a point in the continuum $M$, then the continuum is aposyndetic at $x$ if for every point $y$ in $M-x$, there exists an open set $U$ and continuum $H$ such that $x \in U \subset H \subset M-y$. If $M$ is aposyndetic at $x$ for each point $x$ in $M$, then $M$ is aposyndetic, and $M$ is nonaposyndetic if there is a point $x$ in $M$ such that $M$ is not aposyndetic at $x$. By this definition a degenerate continuum is an aposyndetic continuum. The set $S$ in $M$ is said to separate $M$ if $M-S$ is not connected and is said to cut $M$ if for some pair of points $x, y \in M-S$, every subcontinuum of $M$ intersecting both $x$ and $y$ must also intersect $S$. If every pair of points in $M$ is contained in some simple closed curve lying in $M$, then $M$ is cyclically connected. The continuum $M$ is hereditarily locally connected if $M$ is locally connected and every subcontinuum of $M$ is locally connected, and $M$ is hereditarily aposyndetic if it as well as each of its subcontinua is aposyndetic. In what follows, a subcontinuum of $M$ is aposyndetic or nonaposyndetic if, with the relative topology from $M$, it is aposyndetic or nonaposyndetic respectively.

Bing has proved that if a continuum that is separated by no subcontinuum is aposyndetic at a point, it is locally connected at the 
point [1, Th. 2]. The next theorem shows that the same conclusion follows if the continuum is separated by no nonaposyndetic subcontinuum.

THeOREM 1. Suppose the compact, metric continuum $M$ is separated by no nonaposyndetic subcontinuum. If $M$ is aposyndetic at $x$, then $M$ is locally connected at $x$.

Proof. The continuum $M$ is aposyndetic at each point of $M-x$ with respect to $x$. To see this let $y$ be any point in $M-x$. Since $M$ is aposyndetic at $x$ there exists a continuum $H$ such that $x \in H^{\circ} \subset H \subset M-y$. If $M-H$ is connected then $y \in M-H \subset \overline{M-H} \subset M-x$ and $M$ is aposyndetic at $y$ with respect to $x$. Suppose that $M-H=$ $A+B$, a separation, with $y$ in $B$. Now $H+B$ is a continuum and if $B$ is connected, then $y \in B \subset \bar{B} \subset M-x$ and again $M$ is aposyndetic at $y$ with respect to $x$. So let $B=C+D$, a separation, with $y$ in $D$. Now $D+H$ is a continuum separating $M$ into $A$ and $C$. Hence $D+H$ is aposyndetic at $y$ with respect to $x$ and therefore so is $M$.

In the proof that $M$ is locally connected at $x$ no generality will be lost by assuming $x$ to be a nonseparating point of $M$. For if $x$ separates $M$, then each component $C$ of $M-x$ is an open set, $C+x$ is a continuum with $x$ a nonseparating point, and the proof would be complete by showing that $C+x$ is locally connected at $x$.

First let us show that $M$ is connected im kleinen at $x$. Let $K$ be a closed set in $M$ such that $x \notin K$. Because $M$ is aposyndetic at each point of $K$ with respect to $x$, every point of $K$ is in the interior of a continuum that does not intersect $x$, and by compactness $K$ is in the interior of the sum of a finite number of these continua. For each pair of this finite collection of continua, there exists a continuum in $M-x$ intersecting both, due to the fact that $x$ does not separate and hence does not cut $M$. Therefore, $K$ lies in the interior of a continuum $L$ that does not contain $x$.

We need to show that there is a continuum $H$ such that $x \in H^{\circ} \subset H \subset M-K$. Assume such a continuum does not exist. Then $M-L$ is not connected and is the sum of separated sets $A$ and $B$ with $x$ in $A$. The point $x$ is not in the interior of the component $C$ of $A$ containing it, so there exists a sequence of points $x_{1}, x_{2}, \ldots$ converging to $x$ each point of which belongs to a different component $C_{i}$ of $A$. Let $K_{i}$ be an irreducible subcontinuum of $\bar{C}_{i}+L$ from $x_{i}$ to $L$. Now $K_{i}+L$ separates $M$ and $K_{i}+L$ is therefore aposyndetic. Because $K_{i}$ is irreducible from $x_{i}$ to $L, K_{i} \cdot L$ is degenerate and $K_{i}$ is an aposyndetic continuum. Since every point in $K_{i}-\left(x_{i}+L\right)$ is a cut point of $K_{i}$, everyone of these points must be a separating point of $K_{i}$ and hence $K_{i}$ is an arc. Let $K^{\prime}=\lim \sup K_{i}$ (it is possible 
to construct the $K_{i}^{\prime}$ s so that $\left.K^{\prime} \cdot \sum K_{i}=\varnothing\right)$. Now let us show that the continuum $K^{\prime}+\sum K_{i}+L$ is not aposyndetic at $x$. Let $y_{i}=K_{i} \cdot L$ and let $y$ be a limit point of $y_{1} y_{2}, \cdots$ in $K^{\prime} \cdot L$. If in $K^{\prime}+\sum K_{i}+L$ there were a continuum $H$ with $x$ in its interior that did not contain $y$, then there would exist an integer $n$ such that

$$
\left(H \cdot K_{n}\right)+\left(H \cdot\left[\left(K^{\prime}+\sum K_{i}+L\right)-K_{n}\right]\right)
$$

is a separation of $H$. So $K^{\prime}+\sum K_{i}+L$ is not aposyndetic at $x$ with respect to $y$. Hence this continuum does not separate $M$ and therefore $A+L=K^{\prime}+\sum K_{i}+L$. So $A+L$ is a continuum not aposyndetic at $x$ with respect to $y$. But this means that $M$ is a continuum that is not aposyndetic at $x$ with respect to $y$. For if, on the contrary, $H$ is a continuum in $M$ such that $x \in H^{\circ} \subset H \subset M-y$, then $H \cdot B \neq \varnothing$ or else $A+L$ is aposyndetic at $x$ with respect to $y$. Due to the fact that $L$ is an aposyndetic contiuum (it separates $M$ ), $H \cdot L$ is contained in the sum $S$ of a finite number of continua of $L$ each of which misses $y$. Now $H-S=P+Q$, a separation, with $x \in P \subset A$ and $Q \subset B$. But $P+S$ has a finite number of components since $S$ does and therefore $x$ lies in the interior of the component of $P+S$ containing $x$. This means that $A+L$ is aposyndetic at $x$ with respect to $y$ which is false. Thus $M$ cannot be aposyndetic at $x$ and this contradiction shows that $M$ is connected im kleinen at $x$.

Finally, let us show that $M$ is locally connected at $x$. Let $C$ be a subcontinuum such that $M-C=A+B$, a separation of $M$ (if no such subcontinuum exists, then $M$ is locally connected at $x$ as remarked earlier). If $x \in C$, then because $M$ is connected im kleinen at $x$, there exists a continuum $H$ such that $x \in H^{0} \subset H$ and $C+H$ separates $M$. So $C+H$ is aposyndetic and so is $M$ at each interior point of $C+H$. Therefore $M$ is connected im kleinen at each interior point of $C+H$ which means that $M$ is locally connected at $x$. If $x \in A$ and $A+C$ is not irreducible about $x+C$, then by the above argument, $M$ is locally connected at $x$. On the other hand, if $A+C$ is irreducible about $x+C$, then it is well known that $M$ is locally connected at $x$. This completes the proof of the theorem.

In $[4$, Th. 5] it is shown that the notions of hereditary aposyndesis and hereditary local connectedness are equivalent. The next theorem uses the result of Theorem 1 to establish a stronger characterization of hereditarily locally connected continua.

THEOREM 2. A compact, metric continuum $M$ is hereditarily locally connected if and only if $M$ is an aposyndetic continuum that is separated by no nonaposyndetic subcontinuum.

Proof. Let us prove the sufficiency. The necessity is trivial. 
Since a continuum is hereditarily locally connected if and only if it is hereditarily aposyndetic, it is sufficient for us to prove that $M$ contains no nonaposyndetic subcontinuum. Assume that $M$ contains the nonaposyndetic subcontinuum $N$. The continuum $M$ is aposyndetic and hence, by Theorem 1 , is locally connected. Let $y$ be any point in $M-N$, let $U$ be an open set such that $y \in U \subset \bar{U} \subset M-N$, and let $C$ be the component of $M-y$ containing $N$. Let $V_{1}, V_{2}, \cdots, V_{m}$ be connected open sets of $C$ such that $(\bar{U}-U) \cdot C$ is a subset of $\sum V_{i}$ and $\bar{V}_{i} \cdot(y+N)=\varnothing, 1 \leqq i \leqq m$. Denote by $A_{i}, 1 \leqq i \leqq m$, an arc that intersects $V_{i}$, does not contain $y$, and has only an end point in common with $N$.

Because $N$ is not an aposyndetic continuum, there exist points $p$ and $q$ in $N$ such that $N$ is not aposyndetic at $p$ with respect to $q$. Now in the continuum $N^{\prime}=N+\sum \bar{V}_{i}+\sum A_{i}$, the set $\sum \bar{V}_{i}+\sum A_{i}$ has only a finite number of points in common with $N$ and therefore $N^{\prime}$ cannot be aposyndetic at $p$ with respect to $q$. Furthermore the set $(\bar{U}-U) \cdot C$ separates $M$ into sets $E$ and $F$ with $y \in E$ and $N \subset F$. Since the continuum $N^{\prime}$ contains $(\bar{U}-U) \cdot C$ but not $y$, then $F \subset N^{\prime}$ because $N^{\prime}$ is nonaposyndetic and cannot separate $M$. But $M$ is locally connected at $p$; consequently there is a connected open set $V$ in $M$ containing $p$ and lying in $F$ such that $q \notin \bar{V}$. This means that $N^{\prime}$ is aposyndetic at $p$ with respect to $q$ and this contradiction establishes the theorem.

Another result due to Bing [1, Th. 10] is that a continuum is a simple closed curve if it is separated by no subcontinuum and cut by no point. Next this is generalized to continua not separated by any nonaposyndetic subcontinuum.

THEOREM 3. A compact, metric continuum $M$ is both hereditarily locally connected and cyclically connected if and only if $M$ is separated by no nonaposyndetic subcontinuum and cut by no one of its points.

Proof. Again the proof of necessity is trivial so let us turn to the sufficiency. All we need to prove is that the continuum is aposyndetic because then, by Theorem $2, M$ will be hereditarily locally connected and since no point cuts $M$, then no point separates $M$ and continua of this type are cyclically connected [3, p. 138].

Let us suppose that $M$ is not aposyndetic at a point $x$ in $M$. According to a theorem of Jones' [2, Th. 18] if no point cuts $M$, then $M$ is aposyndetic on a dense subset of $M$. Let $y, z$ be two points at which $M$ is aposyndetic. By Theorem 1 there exist continua $H$ and $K$ neither of which contains $x$ such that $y \in H^{\circ} \subset H, z \in K^{\circ} \subset K$, and $H \cdot K=\varnothing$. If $M-(H+K)$ is connected, then $x$ is in the interior 
of the continuum $\overline{M-(H+K)}$ that separates $y$ from $z$ in $M$. So this continuum and therefore $M$ itself is aposyndetic at $x$. Thus we can assume that $M-(H+K)=A+B$, a separation of $M$. One of the sets, $H+A+K$ or $H+B+K$, must be a continuum. Let us show that the other is also a continuum. Let $H+A+K$ be a continuum and suppose that $H+B+K=P+Q$, a separation, with $H \subset P$ and $K \subset Q$. Now $H+A+K$ is not irreducible about $H+K$ or else points in $A$ will cut points in $P$ from points in $Q$. Let $T$ be a proper subcontinuum of $H+A+K$ containing $H+K$. If $P-H \neq$ $\varnothing \neq Q-K$, then the continua $H+A+K, P+T$ and $Q+T$ all separate $M$ and hence are aposyndetic continua. This means that $M$ is aposyndetic at each point of $A+B$. But this is impossible since $x$ lies in $A+B$.

Suppose $P-H=\varnothing$ so that $P=H, Q=K+B$, and assume that the point of nonaposyndesis $x$ is in $B$. The continuum $Q$ is not irreducible about $x+K$ or else in $M$ a point of $B$ will cut $x$ from a point of $K$. Let $T$ be a proper subcontinuum of $Q$ containing $x+K$. By the above argument $Q-T$ is connected. Let the decomposable continuum $\overline{Q-T}$ be written as the sum of continua $X$ and $Y$. Both $X$ and $Y$ must intersect $T$ or else $x$ is in the interior of a continuum $X+T$ or $Y+T$ that separates $M$, and hence $M$ is aposyndetic at $x$. So $X \cdot T \neq \varnothing \neq Y \cdot T$ and therefore each continuum $X+T$ and $Y+T$ separates $M$. Thus each is aposyndetic, so is the sum $Q$, and this means that $M$ is aposyndetic at $x$. Hence $x$ cannot lie in $B$ and must be in $A$. If $A$ is connected, then $\bar{A}$ separates $M$ and $M$ is aposyndetic at $x$. On the other hand, if $A$ is not connected, then each point of $A$ is in the interior of some continuum that separates $M$ and hence is in the interior of an aposyndetic continuum. This shows then that $M$ is aposyndetic at each point of $A+B$ and means that the supposition that $H+B+K$ is not connected is false. So $H+B+K$ as well as $H+A+K$ is a continuum.

If $H+A+K$ and $H+B+K$ are both irreducible about $H+K$, then let us show that the upper semi-continuous decomposition $H^{\prime}$, whose elements are points of $A$ together with the sets $H$ and $K$, is an arc. To do this let us use the result that if the compact, metric continuum $M$ is irreducible about two of its points $a$ and $b$ such that no point of $M$ (including $a$ and $b$ ) cuts any other point of $M$ from $a+b$, then $M$ is an arc [1, Th. 6]. In our case because $M$ contains no cut points, no point of $A$ cuts any other point of $A$ from $H+K$ in $H+A+K$. In addition neither $H$ nor $K$ cuts the other from a point of $A$ in $H+A+K$. This means that the decomposition $H^{\prime}$ is an arc and since $H+B+K$ is also irreducible about $H+K$, then it can be similarly decomposed into an arc $K^{\prime}$. But then $M$ would be aposyndetic at each point of $A+B$ which is impossible. So we can 
assume that $H+A+K$ or $H+B+K$ is not an irreducible continuum about $H+K$.

Let $N$ be an irreducible subcontinuum of $H+A+K$ about $H+K$ and let $p$ be a point of $A-N$ at which $M$ is aposyndetic. Let $q$ be any point of $B$ at which $M$ is aposyndetic. Now $M$ is connected im kleinen at both $p$ and $q$. Therefore there exist continua $P$ and $Q$ such that $p \in P^{\circ} \subset P, q \in Q^{\circ} \subset Q, P \subset A-(N+x)$ and $Q \subset B-x$. By the above argument $M-(P+Q)=C+D$, a separation of $M$, where $P+C+Q$ and $P+D+Q$ are continua. Since $N \cdot(P+Q)=\varnothing, N$ lies in $C$. So $(P+D+Q) \cdot N=\varnothing$ and therefore $P+D+Q \subset A+B$. This is impossible since $p \in P \cdot A$ and $q \in Q \cdot B$. Thus the assumption that $M$ contains a point at which $M$ is not aposyndetic has led to a contradiction and the proof is complete.

CoRollary (Bing). If the compact, metric continuum $M$ is separated by no subcontinuum and cut by no point, then $M$ is a simple closed curve.

This follows easily as an application of Theorem 3.

\section{BIBLIOGRAPHY}

1. R. H. Bing, Some characterizations of arcs and simple closed curves, Amer. J. Math. 70 (1948), 497-506.

2. F. B. Jones, Concerning nonaposyndetic continua, Amer. J. Math. 70 (1948), 403-413.

3. R. L. Moore, Foundations of point set theory, Amer. Math. Soc. Colloquium Publications, vol. 13, New York, Amer. Math. Society, 1932.

4. E. J. Vought, A classification scheme and characterization of certain curves, Colloq. Math. 20 (1968), 91-98.

Received January 9, 1969.

California State Polytechnic College

POMONA, CALIFORNia 


\section{PACIFIC JOURNAL OF MATHEMATICS}

\section{EDITORS}

H. ROYDEN

Stanford University

Stanford, California

Richard Pierce

University of Washington

Seattle, Washington 98105
J. DUGUNDJI

Department of Mathematics

University of Southern California

Los Angeles, California 90007

BASIL GORDON

University of California

Los Angeles, California 90024

\section{ASSOCIATE EDITORS}
E. F. BECKENBACH
B. H. NEUMANN
F. WOLF
K. YosHIDA

\section{SUPPORTING INSTITUTIONS}

UNIVERSITY OF BRITISH COLUMBIA

CALIFORNIA INSTITUTE OF TECHNOLOGY

UNIVERSITY OF CALIFORNIA

MONTANA STATE UNIVERSITY

UNIVERSITY OF NEVADA

NEW MEXICO STATE UNIVERSITY

OREGON STATE UNIVERSITY

UNIVERSITY OF OREGON

OSAKA UNIVERSITY

UNIVERSITY OF SOUTHERN CALIFORNIA
STANFORD UNIVERSITY

UNIVERSITY OF TOKYO

UNIVERSITY OF UTAH

WASHINGTON STATE UNIVERSITY

UNIVERSITY OF WASHINGTON

*

AMERICAN MATHEMATICAL SOCIETY CHEVRON RESEARCH CORPORATION TRW SYSTEMS

NAVAL WEAPONS CENTER 


\section{Pacific Journal of Mathematics}

\section{Vol. 31, No. $1 \quad$ November, 1969}

James Burton Ax, Injective endomorphisms of varieties and schemes........

Richard Hindman Bouldin, A generalization of the Weinstein-Aronszajn

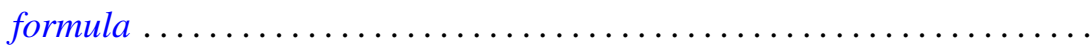

John Martin Chadam, The asymptotic behavior of the Klein-Gordon equation with external potential. II ...............................

Rina Hadass, On the zeros of the solutions of the differential equation

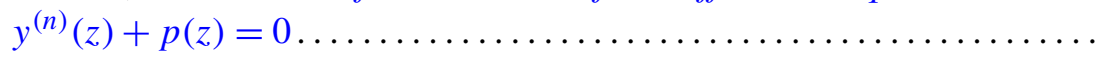

John Sollion Hsia, Integral equivalence of vectors over local modular lattices. II .............................................

Robert Hughes, Boundary behavior of random valued heat polynomial

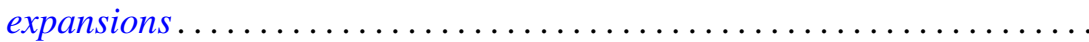

Surender Kumar Jain, Saad H. Mohamed and Surjeet Singh, Rings in which every right ideal is quasi-injective .........................

T. Kawata, On the inversion formula for the characteristic function .........

Erwin Kleinfeld, On right alternative rings without proper right ideals......

Robert Leroy Kruse and David Thomas Price, On the subring structure of

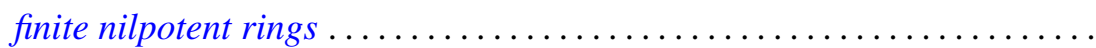

Marvin David Marcus and Stephen J. Pierce, Symmetric positive definite multilinear functionals with a given automorphism. .

William Schumacher Massey, Pontryagin squares in the Thom space of a bundle...

William Schumacher Massey, Proof of a conjecture of Whitney ...

John William Neuberger, Existence of a spectrum for nonlinear transformations

Stephen E. Newman, Measure algebras on idempotent semigroups ...

$\mathrm{K}$. Chandrasekhara Rao, Matrix transformations of some sequence spaces

Robert Bruce Schneider, Some theorems in Fourier analysis on symmetric

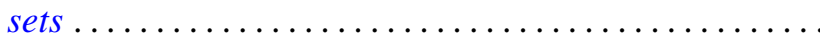

Ulrich F. K. Schoenwaelder, Centralizers of abelian, normal subgroups of hypercyclic groups...

Jerrold Norman Siegel, $G$-spaces, $H$-spaces and $W$-spaces

Robert Irving Soare, Cohesive sets and recursively enumerable Dedekind cuts...

Kwok-Wai Tam, Isometries of certain function spaces .... . .

Awadhesh Kumar Tiwary, Injective hulls of semi-simple modules over regular rings ....

Eldon Jon Vought, Concerning continua not separated by any nonaposyndetic subcontinuum .................... 